\title{
Should all rheumatologists study musculoskeletal anatomy?
}

\author{
Stavros Savvas $^{1,2}$ • Richard S. Panush ${ }^{1,2}$
}

Received: 10 April 2015 / Accepted: 12 April 2015 /Published online: 26 April 2015

(C) International League of Associations for Rheumatology (ILAR) 2015

Keywords Bedside examination · Clinical anatomy · Humanism · Medical humanities · Musculoskeletal anatomy · Physical examination

"I didn't say it was good for you", the King replied. "I said there was nothing like it."

Lewis Carroll, Through The Looking Glass

Should all rheumatologists study musculoskeletal anatomy? Why even ask - isn't the answer obvious? So, then why don't we? Is it the exigencies of practice? The regulatory burdens in our professional lives? The intellectual allure of molecular genetics and biology? The promise of "personalized" healthcare? An acceptance that increasingly sophisticated technological and imaging advances make oldfashioned "bedside" clinical medicine passé? An erosion of humanism in medicine? What really does the study of musculoskeletal anatomy in rheumatology mean? Should we be doing this? And, if so, why?

Presented in part at the Clinical Anatomy Study Group (ST008), American College of Rheumatology Annual Meeting, Boston MA, November 172014 (“A Clinical Scholar's Perspective”)

Richard S. Panush

panush@usc.edu

1 Division of Rheumatology, Department of Medicine, Keck School of Medicine at USC, University of Southern California, Los Angeles, CA 90033, USA

2 LAC + USC Medical Center, Los Angeles, CA 90033, USA
Our colleagues, Juan Canoso, Robert Kalish, Pablo Villasañor-Ovies, Chris Evelyn, Karina Torralba, and others, assert that teaching and learning musculoskeletal anatomy is fundamental to rheumatologic practice and education [1-7]. We greatly respect the passion and commitment of our learned friends. In this commentary, we offer the perspective of sympathetic yet largely uninvolved and dispassionate observers. We shall try to place the study of musculoskeletal anatomy in a context of contemporary rheumatology, challenge its advocates to additional and broader studies, and suggest future directions.

Is there more to this than just study of musculoskeletal anatomy? We think that knowing musculoskeletal anatomy says something profound about who we are, our identity, how we wish to be perceived, how we should teach and practice our specialty, and how we want to do this responsibly in today's society. We think this view mirrors Goethe's "was man sieht, man weisst" (what we see, we know), that "knowing is better than not knowing - every time" (Cassandra Clare, City of Glass), and the wisdom of that great baseball player, Yogi Berra, who said that "if you don't know where you are going, you may never get there". We think this view asserts that good doctoring and good care are predicated on informed evaluation, which must begin with knowledge of musculoskeletal anatomy (Table 1).

Might study of musculoskeletal anatomy make us better, perhaps even more humanistic, physicians? Osler taught, as Verghese et al. have recently reminded us, that "the whole art of medicine is in observation... (that) eliciting the history and performing the physical examination" was the most important means of diagnosis. Osler called it one of the "principles of practice". He implored us to "remember... that every patient... will examine you critically and form an estimate of you by the way in which you conduct yourself at the bedside. Skill and nicety in (examination)... will do more towards 
Table 1 Studying musculoskeletal anatomy as a "first principle", as an existential reflection of rheumatology and rheumatologic practice and education

"Was man sieht, man weisst" (Goethe \{what we see, we know\}); "knowing is better than not knowing — every time" (Cassandra Clare, City of Glass); "If you don't know where you are going, you may never get there" (Yogi Berra)

Good doctoring and good care are predicated on informed evaluation, which must begin with knowledge of the rheumatologic/musculoskeletal anatomy

"The whole art of medicine is in observation" (Osler [9, 10]); "eliciting the history and performing the physical examination" is the most important means of diagnosis - one of the "principles of practice" (Osler [8-10]); skill and nicety in (examination)... will do more towards establishing confidence in you than... diplomas... reputation... (or) experience" (Osler [8-10])

Touching is the "real professional secret... the oldest and most effective act of doctors" (Lewis Thomas [11, 12])

Can we effectively "touch" patients or even "observe" without knowing what it is we touch and see?

"Physicians who forgo or circumvent the bedside evaluation risk the loss of an important ritual that enhances the physician-patient relationship" (Verghese et al., [8])

Patients expect some form of bedside evaluation upon visiting a physician. Done expertly, it can be salutary; done poorly or omitted, it can undermine the physician-patient relationship [8, 14]; expert bedside evaluation — informed observing and touching — is a powerful healing ritual, earning trust and authority, conveying respect, and reflecting genuine understanding and expertise $[8,14]$

Thorough, informed observation and touching may reasonably be thought to lead to better and less costly care, more patient satisfaction, more physician satisfaction, and better patient outcomes [8]

"Rheumatology achieves a degree of uniqueness by its demands for unsurpassed clinical skills, empathy, intellectual curiosity, humanism, and oldfashioned caring... the 'compleat' rheumatologist appreciates the potency, influence, and symbolic importance of those rituals and ceremonies that reflect the art of our tradition" [13-16]

"The good rheumatologist... recognizes that rheumatology remains inherently a clinical exercise, that good medicine uses science to inform art. We cherish the intimacy and immediacy of our specialty, the ability to understand by talking with and touching patients. We take special pride that our refined clinical skills remain indispensable. The good rheumatologist usually reaches a diagnosis following careful, learned, thoughtful evaluation, and knows that we have a full array of modern diagnostic studies available, but needs and uses them sparingly" [13-16]

"In clinical rheumatology, science does not often substitute for art nor sophisticated technology for diagnostic acumen" [16]; the good rheumatologist knows "the secret of the care of the patient is in caring for the patient"[17]

establishing confidence in you than... diplomas... reputation... (or) experience" [8-10]), to which we might add "or diagnostic studies" (Table 1).

Our colleagues, proposing the essential importance of learning musculoskeletal anatomy, tell us that in rheumatology, as in medicine, Osler's "observation" must be appropriately knowledgeable. Lewis Thomas referred to touching as the "real professional secret" and called it "the oldest and most effective act of doctors"; years ago, he worried that "the close-up, reassuring, warm touch of the physician, the comfort and concern... are disappearing from the practice of medicine" $[11,12]$. Can we in rheumatology effectively "touch" patients or even "observe" them without knowing what it is we touch and see (Table 1)?

Verghese et al. eloquently emended that "physicians often bypass the bedside evaluation for immediate testing" and lamented "... that physicians who forgo or circumvent the bedside evaluation risk the loss of an important ritual that enhances the physician-patient relationship. Patients expect some form of bedside evaluation upon visiting a physician. When physicians complete this evaluation in an expert manner, it can have a salutary effect. If done poorly or not at all, in contrast, it can undermine the physician-patient relationship." $\mathrm{He}$ and colleagues viewed expert bedside evaluation-informed observing and touching - "as a healing ritual and powerful diagnostic tool... earning trust and authority... (which may) affirm the personal commitment between doctor and patient", conveying respect, and reflecting genuine understanding and expertise. Patients miss this ceremony, characterized by the refrain "my doctor never touched me" [8]. Today that art has eroded. It has been said that if a patient came to an emergency room with an amputated finger, a hand magnetic resonance imaging (MRI) would be obtained to confirm the missing digit. Thorough informed observation and touching, Verghese et al. posited, leads to better and less costly care, more patient satisfaction, more physician satisfaction, and better patient outcomes (Table 1).

While intuitively the benefits of knowing anatomy in the practice of rheumatology would seem obvious, is there scientifically proven evidence in its support? Essential to advancing and successfully promoting the study of musculoskeletal anatomy is to clearly and convincingly establish practical, clinical value - to document that it adds tangible, meaningful, measurable value to patient care. We are reminded of the imperative, not so long ago, to prove that rheumatologic care "made a difference", to show that it was better than care by other practitioners [18-20]. And we confronted a similar circumstance recently when we first postulated and then experimentally demonstrated the salutary effect of implementing a "bedside humanities" curriculum for medical residents on physician behavior and patient outcomes [21].

We think that claimants for studying musculoskeletal anatomy perceive our specialty in this manner, believing that learning musculoskeletal anatomy is necessary to informed rheumatologic practice and care, believing, as we do and have written [13-16], that "rheumatology achieves a degree of 
Table 2 What is the practical value of studying musculoskeletal anatomy? The big "humongous" questions [18-21]

Essential to advancing and successfully promoting the study of musculoskeletal anatomy is to clearly and convincingly establish practical, clinical value - to document that it adds tangible, meaningful, measurable value to patient care

If learning musculoskeletal anatomy led to demonstrably better, safer, and less costly care, at least for some of our conditions, would it not then be more likely to be embraced among our educational and practice standards?

uniqueness by its demands for unsurpassed clinical skills, empathy, intellectual curiosity, humanism, and old-fashioned caring, that the 'compleat' rheumatologist appreciates the potency, influence, and symbolic importance of those rituals and ceremonies that reflect the art of our tradition". "The good rheumatologist... recognizes that rheumatology remains inherently a clinical exercise, that good medicine uses science to inform art. We cherish the intimacy and immediacy of our specialty, the ability to understand by talking with and touching patients. We take special pride that our refined clinical skills remain indispensable. The good rheumatologist usually reaches a diagnosis following careful, learned, thoughtful evaluation and knows that we have a full array of modern diagnostic studies available, but needs and uses them sparingly. 'In clinical rheumatology, science does not often substitute for art nor sophisticated technology for diagnostic acumen [16].' The good rheumatologist knows science and wisely integrates appropriate advances into patient care. We know that the essence of medicine is the reduction of uncertainty; we tolerate uncertainty and help our patients accept it. Good rheumatologists care for patients with passion, respect, and humane understanding. We know "the secret of the care of the patient is in caring for the patient' [17]" (Table 1).

How might such data be obtained? While the more rigorous the study the better, this could be done reasonably simply for musculoskeletal anatomy, certainly in "pilot" fashion, with a several-hour curriculum, physicians of selected training backgrounds, appropriate controls, and standardized or simulated patients in clinical situations with quantifiable assessments of relevant outcomes (and pertinent costs). If learning musculoskeletal anatomy led to demonstrably better, safer, and less costly care, at least for some of our conditions, would it not then be more likely to be embraced among our educational and practice standards? Our profession, teachers, mentors, society, and medical insurance companies and other third-party payers would indeed be more interested if these benefits were expressed in outcomes such as number needed to prevent one unnecessary MRI study, consultation, surgery, or, even better yet, overall US healthcare dollars saved.

What should be next for the promotion of studying musculoskeletal anatomy? The challenge now, we believe, is to translate these beliefs to certainty- to document and quantify the value of learning musculoskeletal anatomy in contemporary rheumatologic training and practice (Table 2). How is it relevant in 2015? In an era of incredibly sophisticated imaging and other diagnostic technologies, how can we show that we really still need to learn musculoskeletal anatomy? How does it relate to education and training? Practice? How is teaching/ learning musculoskeletal anatomy important and relevant for non-soft tissue rheumatic/musculoskeletal disease? Like lupus? For rheumatologists or programs where soft tissue rheumatic/musculoskeletal diseases are relatively small aspects of the enterprise? Can a good rheumatologist not know this well? Can a good educational program not teach this well? Does it promote humanistic practice? How? Does it contribute to care that is better? Higher value? More cost-conscious? Safer? More timely? More patient-centered? More effective? More efficient? More equitable? More humanistic? More informed? More scientific? More scholarly? More artful? More satisfying to patients? More accountable to society? More excellent? Where are the data? What studies would document

Table 3 Why learn muscuoloskeletal anatomy? Unanswered (or inadequately answered) questions

How is it relevant in $2015 ?$

In an era of incredibly sophisticated imaging and other diagnostic technologies, how can we show that we really still need to learn musculoskeletal anatomy?

How does it relate to education and training? Practice?

How is teaching/learning musculoskeletal anatomy important and relevant for non-soft tissue rheumatic/musculoskeletal disease? For rheumatologists or programs where soft tissue rheumatic/musculoskeletal diseases are relatively small aspects of the enterprise?

Can a good rheumatologist not know this well? Can a good educational program not teach this well?

Does it promote humanistic practice? How?

How is study of musculoskeletal anatomy relevant to healthcare in 2015? Does it contribute to care that is better? Higher value? More cost-conscious? Safer? More timely? More patient-centered? More effective? More efficient? More equitable? More humanistic? More informed? More scientific? More scholarly? More artful? More continually improving? More satisfying to patients? More accountable to society? More excellent?

Where are the data? Are they robust? Confirmed? What studies, or additional studies, would document this cogently?

If study and teaching musculoskeletal anatomy are valuable, is there a curriculum proven effective?

How can this be promoted? Developed? 
this cogently? If studying and teaching musculoskeletal anatomy is valuable, is there a curriculum that is proven to do this effectively? How can this be promoted? "Marketed"? Developed? (Table 3) Made more attractive?

"It is a capital mistake to theorize before one has data. Insensibly one begins to twist facts to suit theories, instead of theories to suit facts."

Arthur Conan Doyle, Sherlock Holmes

Disclosure None.

\section{References}

1. Kalish RA. Clinical anatomy as basic science in rheumatology training. Presented at the Clinical Anatomy Study Group (ST008), American College of Rheumatology Annual Meeting, Boston MA, November 172014

2. Evelyn CE: The clinical anatomy program at the Angeles CountyUniversity of Southern California (LAC+USC) Medical Center. Presented at the Clinical Anatomy Study Group (ST008), American College of Rheumatology Annual Meeting, Boston MA, November 172014

3. Torralba K: Ultrasonography as a teaching tool of musculoskeletal anatomy. Presented at the Clinical Anatomy Study Group (ST008), American College of Rheumatology Annual Meeting, Boston MA, November 172014

4. Villasañor-Ovies P: Development and experience of the Mexican Group for the Study of Clinical Anatomy (GMAC). Presented at the Clinical Anatomy Study Group (ST008), American College of Rheumatology Annual Meeting, Boston MA, November 172014

5. Kalish RA, Canoso JJ (2007) Clinical anatomy: an unmet agenda in rheumatology training. J Rheum 43:1208-1211
6. Kalish RA, Canoso JJ (2012) Development of the seminar. Rheumatol Clin 8(S2):10-12

7. Navarro-Zarza JE, Hernandez-Diaz C, Saavedra MA, Alvarez Nemegyel J, Kalish RA, Canoso JJ, Villasenor-Ovies P (2014) Preworkshop knowledge of musculoskeletal anatomy of rheumatology fellows and rheumatologists of seven North, Central, and South American countries. Arthritis Care Res 66: 270-276

8. Verghese A, Brady E, Kapur CC, Horwitz RI (2011) The bedside evaluation; ritual and reason. Ann Intern Med 155:550-553

9. Silverman EM, Murray TJ, Bryan CS (2007) The quotable Osler. American College of Physicians, Philadelphia, p 99

10. Osler W (1874) Valedictory address to the graduates in medicine and surgery. McGill University. Can Med Surg J 3:433-442

11. Kaplan H (1995) ACR presidential address: my granddaughter, the rheumatologist. Arthritis Rheum 38:451-457

12. Thomas L (1995) The youngest science: notes of a medicine watcher. Aflred P Sloan Foundation Series, Penguin Books

13. Panush RS (2011) Why rheumatology and the care of patients with rheumatic diseases are important, interesting, and exciting. Rheumatologist 5(6):65-72

14. Panush RS (2012) Rituals, symbols, ceremony, and tradition. Rheumatologist 6(1):52-53

15. Sergent JS, Panush RS. Introduction. Current controversies in clinical rheumatology. Rheum Dis Clin. 1993; 19:xv

16. Carias K, Panush RS (1994) Acute arthritis. Bull Rheum Dis 43:1-4

17. Peabody F (1927) The care of the patient. JAMA 88:877-882

18. Panush RS, Kaplan H (1995) Who will care for our patients? J Rheum 22:2197-2199

19. Abraham VJ, Remensone EI, Shapira IT, Siegelbaum RH, Holtz HA, Sigal LH, Kramer N, Paolino JS, Rosenstein ED, Panush RS (1998) What is the fibromyalgia syndrome and why is it important? Rheumatol Musculoskelet Med Prim Care 1:7-14

20. Panush RS, Carias K, Kramer N, Rosenstein ED (1995) Acute arthritis in the hospital: comparison of rheumatologic with nonrheumatologic care. J Clin Rheum 1(2):74-80

21. Panush RS (2011) Why I sometimes read poetry instead of medicine - and why you should too. Rheumatologist 5:47-49 